\title{
A instrução pública e a escola primária paranaense nas charges de OOlho da Rua
}

\author{
The public education and the Paranás primary school \\ in the cartoons of O Olho da Rua
}

La instrucción pública y la escuela primaria paranaense en las caricaturas de O Olho da Rua

WANESSA GORRI DE OLIVEIRA (Da

ELAINE RODRIGUES (Db

\section{Resumo}

Este artigo se insere no campo de pesquisa de história da educação no Paraná. A pesquisa toma a revista $O$ Olho da Rua como fonte e objeto investigativo e o recorte temporal converge para o ciclo de vida do periódico, entre os anos de 1907 e 1911. Por meio de algumas charges veiculadas, o artigo então mostra como O Olho da Rua (1907-1911) se constituiu como um suporte material e meio de difusão do que era considerado retrógrado na instrução pública e no fazer prático da escola primária no início do século XX no estado do Paraná. Com base em quatro dessas charges sobre a instrução pública e os encaminhamentos práticos vigentes nas escolas primárias paranaenses, o principal dessa reflexão está direcionado para a seguinte problematização: - Como as charges de $O$ Olho $d a$ Rua propuseram interpretações sobre a instrução pública paranaense e sobre o fazer prático da escola primária? Para responder a essa problematização, a história cultural baliza a manipulação do corpus documental e a semiótica orienta a análise das charges selecionadas. As charges demonstram que a instrução pública e a escola primária necessitavam de um redirecionamento para que promovessem uma instrução articulada com a educação cívica, laica e anticlerical. Esse redirecionamento sugerido pelos chargistas de $O$ Olho da Rua se aproximava das ideias defendidas pelo republicano Dario Vellozo (1886-1937), um dos representantes da pedagogia moderna no Estado do Paraná.

Palavras-chave: Revista O Olho da Rua. Instrução pública. Escola primária. Educação cívica. Anticlericalismo.

\footnotetext{
a Universidade Estadual do Paraná (UNESPAR), Campo Mourão, PR, Brasil. Mestre em Educação, e-mail: nessag12@hotmail.com

b Universidade Estadual do Paraná (UNESPAR), Maringá, PR, Brasil. Doutora em História, e-mail: elaineppeuem@gmail.com
} 


\begin{abstract}
This article is part of the field of research on the history of education in Paraná. The research takes the O Olho da Rua magazine as a source and investigative object. The temporal clipping converges into the life cycle of the magazine itself, between 1907 and 1911. Through some cartoons served, the article shows how O Olho da Rua (1907-1911) constituted itself as material support and means of dissemination of what was considered retrograde in public education and in the practical making of primary school in the early XX century in the state of Paraná. Based on four of these cartoons about public education and the practical referrals in Paranás elementary schools, the main part of this reflection is towards to the following problematization: How the $O$ Olho da Rua's cartoons proposed interpretations about the Paraná public education and about the practical practice of primary school? In order to answer this question, the cultural history beacon the manipulation of the documentary corpus and the semiotics guides the analysis of the selected cartoons. These cartoons show that public education and primary schools need redirection in order to promote an articulated education with civic, secular and anticlerical education. This redirect suggested by the cartoonists of $O$ Olho da Rua was close to the ideas defended by Republican Dario Vellozo (1886-1937), one of the representatives of modern pedagogy in the State of Paraná.
\end{abstract}

Keywords: O Olho da Rua magazine. Public education. Primary school. Civic education. Anticlerisism.

\title{
Resumen
}

Este artículo se inserta en el campo de investigación de la historia de la educación en Paraná. La investigación toma la revista $O$ Olho da Rua como fuente y objeto investigativo y el recorte temporal se dirige para el ciclo de vida del periódico, entre los años 1907 y 1911. A través de algunas caricaturas vehiculadas, el artículo entonces muestra cómo O Olho da Rua (19071911) se constituyó como un soporte material y medio de difusión en lo que era considerado retrógrado en la instrucción pública y en el hacer práctico de la escuela primaria a principios del siglo XX en el estado de Paraná. Con base en cuatro de esas caricaturas sobre la instrucción pública y los encaminamientos prácticos vigentes en las escuelas primarias paranaenses, lo principal de esa reflexión está dirigido a la siguiente problematización: -Como las caricaturas de $O$ Olho da Rua propusieron interpretaciones sobre la instrucción pública paranaense y sobre el hacer práctico de la escuela primaria? Para responder a esa problematización, la historia cultural baliza la manipulación del corpus documental y la semiótica orienta el análisis de las caricaturas seleccionadas. Las caricaturas demuestran que la instrucción pública y la escuela primaria necesitaban una redirección para promover una instrucción articulada con la educación cívica, laica y anticlerical. Esta redirección sugerida por los dibujantes de $O$ Olho da Rua se acercaba a las ideas defendidas por el republicano Dario Vellozo (1886-1937), uno de los representantes de la pedagogía moderna en el Estado de Paraná.

Palabras-clave: Revista O Olho da Rua. Instrucción pública. Escuela primaria. Educación cívica. Anticlericalismo. 


\section{Introdução}

Neste artigo objetiva-se mostrar que a Revista O Olho da Rua (1907-1911) se constitui como um suporte material e meio de difusão do que era considerado retrógrado na instrução pública e no fazer prático da escola primária, no início do século XX no estado do Paraná. A Revista O Olho da Rua, periódico curitibano da grande imprensa, republicano e anticlerical, registrou discursos combatentes dirigidos à instrução pública e à escola primária no Paraná, utilizando-se de humor, sátiras, ironias e metáforas.

A escrita da história da educação do Paraná, ora proposta, com base no periódico O Olho da Rua, parte do pressuposto de que, para a história cultural, se faz necessário voltar atenção para a materialidade dos suportes dos textos, pois não existe nenhum texto fora de um suporte que o dá a ler; não há nenhum escrito que não dependa das formas de como chega ao leitor. As obras ganham sentido nessa dupla relação e isso não deve passar despercebido aos pesquisadores empenhados em investigações cujo foco atravessa um determinado objeto, pois cada categoria de textos pressupõe uma forma específica de leitura (CERTEAU, 1982; CHARTIER, 1988, 1998, 2002a, 2002b).

Como suporte material, a revista $O$ Olho da Rua, na condição de corpus documental desta pesquisa, será manipulada como fonte e objeto de investigação devido ao fato de ser uma fonte rica para o conhecimento do passado (CAPELATO, 1998; LUCA, 2005). Especificamente, quatro charges contidas no periódico fornecerão matéria-prima para o encaminhamento das análises que serão desdobradas de seus conteúdos — explicitamente e implicitamente apresentados.

As quatro charges que serão priorizadas como porta de entrada para as análises subsequentes, são: 1) "Charge de Shetos sobre a aprovação do novo Regulamento de Instrução Pública em 1908” (O OLHO DA RUA, n. 19, 18 de janeiro de 1908, s.p.), 2) "Instrução" (O OLHO DA RUA, n. 3, 11 de maio de 1907, s.p.), 3) "Charge Nhê resuma", de Sylvio, sobre uma escola de freiras polonesas em Curitiba (O OLHO DA RUA, n. 4, 25 de maio de 1907, s.p.) e 4) "Charge Collegio Religioso de Palmas", elaborada por H (O OLHO DA RUA, n. 11, 7 de setembro de 1907). 
Embasando-se nessas charges, o principal desta reflexão está direcionado para a seguinte problematização: - Como as charges de O Olho da Rua propuseram interpretações sobre a instrução pública paranaense e sobre o fazer prático da escola primária? Há de se destacar, portanto, que problematizar um trabalho históricoeducacional é ponto central e é essa problematização que fornece subsídios para a escrita da história da educação, justamente porque as fontes não "falam" sozinhas — só falam se e quando problematizadas (BLOCH, 2001; CERTEAU, 1982). Diante dessa problematização, a história cultural balizará a manipulação do corpus documental com Chartier (CHARTIER, 1988, 1998, 2002a, 2002b) e a semiótica orientará a análise das charges com base em Santaella (1983; 2005) e Joly (1996).

Assim, este artigo primeiramente destacará que, após o advento da República, os estados brasileiros ficaram responsáveis por manter, prioritariamente, a escolarização primária. Na sequência analisará as charges selecionadas com o intuito de enfatizar a interpretação produzida pela revista $O$ Olho da Rua sobre a instrução pública e escola primária no início da República no Paraná.

\section{0 advento da república e a escola primária no Paraná}

$\mathrm{Na}$ virada do século XIX para o século XX, ficou mais claramente delineado um esforço do Brasil e do Paraná na busca pela modernização e na pretensão de desenvolvimento político e cultural encabeçado pela elite.

No empenho direcionado à modernização, as elites buscavam reduzir os efeitos das mazelas herdadas do colonialismo e da escravidão e que estavam desdobradas por toda a realidade social brasileira. Para isso, pautou-se nos modelos europeus ou norte-americanos de gestão social. Esses modelos apregoavam os estereótipos de civilização, de urbanismo científico e de crença na efetividade do progresso. O novo regime político era propagado como portador da capacidade de cancelar toda a herança do passado histórico e, pela mera reforma institucional, poderia firmar um nexo coextensivo entre a sociedade e a cultura das potências mundiais já industrializadas (SEVCENKO, 1998).

Na visão de Sevcenko (1998), as elites republicanas levaram certo tempo para compreender, de forma crítica, os fenômenos de subdesenvolvimento e das 
desigualdades existentes no sistema de troca no mercado internacional. Enquanto a consciência crítica não fora desenvolvida, prevalecia o sentimento de desprezo, de vergonha, de aversão em relação ao passado, aos grupos “atrasados” da sociedade e à cultura que evocava hábitos do passado a serem superados pelos republicanos, como se fosse possível fazer uma assepsia no passado e constituir uma "nova" nação com lustros europeus.

Além disso, a Proclamação da República modificou a organização política de várias províncias, dentre elas a do Paraná, que foi transformada em um dos estados federados da nação. O estado do Paraná, assim como outros estados brasileiros, centralizou a necessidade de difundir a instrução pública aos cidadãos como um elemento essencial para a consolidação do novo regime político. Assim, quanto aos anos subsequentes à Proclamação da República, é natural esperar que os gestores públicos tivessem elaborado uma diversidade de leis, de decretos e de regulamentos com o intento de reorganizar e de desenvolver a instrução pública e de alfabetizar uma população predominantemente analfabeta, como, aliás, ocorria na nação toda.

Para se ter ideia, a estatística de analfabetos no Brasil no início da República chegou à marca de 80\%, mesma marca registrada no estado do Paraná. Essa estatística gerou nos intelectuais brasileiros um sentimento de vergonha nacional diante dos países considerados mais avançados (SOARES; GALVÃO, 2005; KAMINSKI, 2012).

Schelbauer (1998) afirma que, a partir da última década do século XIX, a escola passou a ser interpretada como a instituição responsável pela construção dos sentimentos de cidadania necessários para inserir o Brasil no rumo do progresso e na fixação da democracia nos parâmetros dos países civilizados. Nesse sentido, se antes o atraso da nação era remetido à escravidão, depois, com a abolição em 1888, o atraso passou a ser atribuído à própria educação, pois não cumpria ou apenas cumpria de modo precário seu papel social. Por isso a educação foi uma das principais frentes de defesa do regime republicano.

A educação como a responsável por alavancar o progresso da nação brasileira, republicana, desenhou-se de forma específica em terras paranaenses no final do século XIX e nos primeiros anos do século XX. Neste estado, o Decreto $n^{\circ} 31$, de 29 de janeiro de 1890 (PARANÁ, 1890), que promulgou determinações para o ensino 
primário, para o Instituto Paranaense e para a Escola Normal, foi o primeiro documento paranaense que anunciou um regulamento de instrução pública após a Proclamação da República. Esse decreto ficou em vigência durante, apenas, três meses (MACHADO, 2011; MACHADO; MELO, 2012; OLIVEIRA, 2006).

Com a Constituição Federal de 1891, promulgada em 24 de fevereiro daquele ano (BRASIL, 1891), houve a adesão do estado do Paraná ao regime federativo, representativo e presidencialista (CURY, 2005). Com base no artigo $\mathrm{n}^{\circ} 35$ dessa Constituição, o governo central ficou responsável pelo ensino secundário e superior em toda a federação e pelo primário e secundário no Distrito Federal. Os estados federados, por sua vez, responsabilizaram-se, prioritariamente, pela criação e manutenção da escola primária em suas regiões, isso porque a instrução primária não fazia parte dos interesses do governo central. O governo central delegou-a aos estados, os estados aos municípios e os municípios às comunidades locais (WACHOWICZ, 1984).

Em 7 de abril de 1892 foi aprovada a Carta Constitucional do Estado do Paraná (PARANÁ, 1892), documento que se apresentou alinhado às prerrogativas constitucionais federais instituídas em 1891. Essa Carta definiu que o Congresso era o responsável por legislar sobre o ensino público e deliberou a oferta do ensino primário como gratuito e generalizado (art. 131). Ocorreu, contudo, que a ênfase na gratuidade não esclarecia o responsável financeiramente pela manutenção do ensino, permitindo a conclusão de que a almejada liberdade de ensino impedia que a obrigatoriedade e sua centralização nas mãos do Estado fosse colocada em questão. Desse modo, a Constituição paranaense elencou a responsabilidade do estado nas questões referidas à educação, de maneira a limitar as obrigações estatais, que deveria ser cuidada e amparada para maior desenvolvimento da sociedade paranaense, sem impedir a livre iniciativa (MACHADO; MELO, 2012).

A não definição e/ou não obrigação do Estado na manutenção financeira da instrução era uma contradição. Por um lado, defendia-se a educação dos cidadãos como essencial à alfabetização, à modernização e como aparato para a civilização e, por outro, a não intervenção estatal nas questões educacionais, sobretudo na manutenção financeira - fato complexo para um país de analfabetos e adepto a um novo regime político. 
Salienta-se que o Paraná experimentou uma onda de regulamentos voltados à instrução pública, aprovados e revogados em um curto espaço de tempo. Oliveira (1982) expõe que regulamentos de instrução pública foram aprovados nos anos de 1890, 1891, 1892 e 1901. Esses regulamentos expressaram as descontinuidades das propostas do governo do estado na organização da instrução. Alvo de críticas e de descontentamentos por parte de alguns intelectuais paranaenses, a descontinuidade apresentada pelo excesso de regulamentos fez parte dos discursos disseminados pela revista $O$ Olho da Rua, especificamente em decorrência da aprovação de mais um regulamento, o Regulamento de Instrução Pública, elaborado no ano de 1907 (PARANÁ, 1907).

Em 1907, o Paraná vivenciou o processo de elaboração desse regulamento, depois consubstanciado e aprovado na forma do Decreto $n^{\circ} 479$, de 10 de dezembro daquele ano. Mesmo tendo sido divulgado em 1907, a observância do documento se deu somente a partir de 16 de janeiro de 1908.

Na visão de Wachowicz (1984), esse regulamente teve um tempo de vida curto. Vigorou de 16 de janeiro de 1908 até 28 de fevereiro do mesmo ano. Foi suspenso pelo Congresso Legislativo Estadual sob a alegação de falta de consistência nas bases estabelecidas. Com a suspensão desse regulamento, voltou a vigorar o regulamento de Instrução de 1901 — Decreto no 93/1901 (PARANÁ, 1901).

Esse processo mobilizou o posicionamento da revista $O$ Olho da $\mathrm{R} u a$ a respeito de como o diretor geral de Instrução Pública, Arthur Pedreira de Cerqueira, conduzia a instrução pública paranaense. Essa mobilização apresentou divergências, pois, de um lado, havia a estrutura criada pelo governo do Estado e representada pelo diretor geral de Instrução Pública para a elaboração do regulamento e, do outro lado, havia, no bojo da revista $O$ Olho da Rua, um movimento contrário, divergente das balizas representadas pelo diretor geral. Ou seja, as balizas representadas pelo diretor geral e pela comissão constituída por Álvaro Pereira Jorge, Affonso Teixeira de Freitas e João Pereira Lagos para elaborar o regulamento eram contestadas pelo periódico principalmente por duas razões. Uma delas era a alegação de que a instrução pública proposta era demasiado limitada para a época (não se adequava à pedagogia moderna). A outra razão era o clericalismo nas escolas. 
A ausência de investimento consistente do Estado na instrução pública, principalmente para a instrução voltada à escolarização primária, essencial para a civilização, modernização e pedra de toque para erradicar o analfabetismo, expressouse nas charges de O Olho da Rua.

\section{O Olho da Rua e suas charges: interfaces da instrução pública e da escola primária}

Primeiramente, há de se destacar que a perspectiva defendida pela revista $O$ Olho da Rua por meio das charges consistiu em apenas uma dentre diversas representações culturais em confluência no estado do Paraná no início do século XX. A respeito da concepção de representação cultural, Chartier $(1988,1998)$ demonstra que essa concepção se trata da representação balizada pelos interesses de um determinado grupo que busca sobrepor seus valores e conceitos aos demais grupos. Desse modo, uma determinada representação se relaciona à posição ocupada pelos sujeitos num determinado momento histórico, sempre em luta ou em debate com as demais representações. Nesse viés, cada grupo produz uma noção de real compatível a um mesmo fenômeno vivido pela sociedade e se insere na disputa em decorrência da posição social ocupada. É nesse sentido que se compreendem as críticas e as reflexões desdobradas do periódico como uma representação cultural específica.

Para a análise das charges, a semiótica balizará as reflexões propostas. A semiótica é um campo do conhecimento que auxilia a interpretação das imagens. Para Santaella $(1983 ; 2005)$, a semiótica é uma ciência cujo objeto é investigar as diversas linguagens possíveis e objetiva analisar os modos pelos quais se estruturam os fenômenos como produtores de significação e sentido. A semiótica permite ao pesquisador adentrar no movimento interno das mensagens e entender o emprego dos recursos utilizados numa determinada imagem.

A imagem é uma forma de comunicação. Como forma de comunicação, é colocada em circulação com a sua referencialidade firmada como ícone, índice ou símbolo. A imagem tratada como ícone se dá em decorrência da sua capacidade de referencialidade ou de a mensagem originar-se apenas da predominância sugestiva em seus aspectos sensoriais. O ícone envolve uma relação de analogia com o que pretende 
representar (o referente). Por exemplo, uma imagem de síntese que represente uma casa é um ícone porque se assemelha a uma casa. A imagem como índice dá-se quando a sua referencialidade é direta, indica sem ambiguidade no mundo existente aquilo a que ela se refere, os indícios do que representa. Para exemplificar, uma imagem que possui a representação de uma pessoa pálida é indicativa da fadiga dessa pessoa. Por sua vez, uma imagem se caracteriza como símbolo quando as mensagens apresentam o poder de representar ideias convencionais, abstratas ou que mantêm com seu referente uma relação de convenção, tal como uma bandeira nacional (SANTAELLA, 2005; JOLY, 1996).

Desse modo, para analisar a mensagem contida em uma imagem o pesquisador necessita colocar-se no lugar, não do autor, mas do receptor, assim como precisa observar historicamente o conteúdo da mensagem. A depender da perspectiva do leitor, uma determinada imagem poderá ser situada como ícone, índice ou símbolo ou ser identificada com características do índice, do ícone ou do símbolo (JOLY, 1996).

Na sequência, a "Charge de Shetos sobre a aprovação do novo Regulamento de Instrução Pública em 1908” (O OLHO DA RUA, n. 19, 18 de janeiro de 1908, s.p.) será tratada como símbolo e as charges "Instrução" (O OLHO DA RUA, n. 3, 11 de maio de 1907, s.p.), "Nhê resuma", de Sylvio, sobre uma escola de freiras polonesas em Curitiba (O OLHO DA RUA, n. 4, 25 de maio de 1907, s.p.) e a “Charge Collegio Religioso de Palmas", elaborada por H (O OLHO DA RUA, n. 11, 7 de setembro de 1907), serão abordadas como ícone, à luz das orientações da semiótica (JOLY, 1996; SANTAELLA, 2005).

A primeira charge demonstra a insatisfação da revista diante da reformulação do Regulamento de Instrução Pública elaborado no ano de 1907 (PARANÁ, 1907). A charge elaborada por Shetos $^{1}$ (Figura 1) e disponibilizada na segunda capa da edição 19, de 18 de janeiro de 1908, dois dias após o Regulamento de Instrução Pública entrar em vigor, expõe:

\footnotetext{
${ }^{1} \mathrm{O}$ nome real do pseudônimo Shetos não foi identificado até o presente momento. 
Figura 1 - Charge de Shetos sobre a aprovação do novo Regulamento de Instrução Pública em 1908

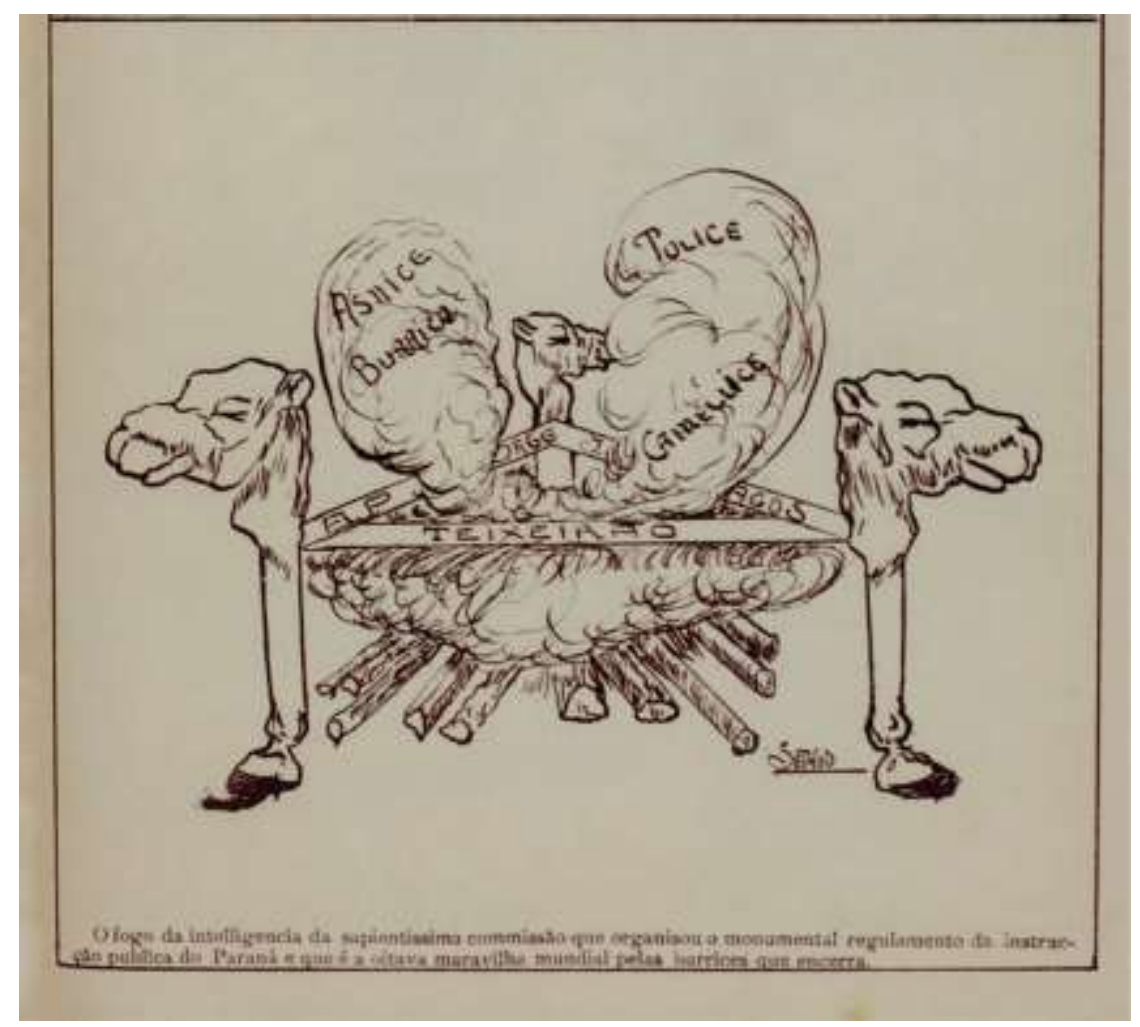

Fonte: O Olho da Rua, n. 19, 18 de janeiro de 1908, s.p.

Essa charge utilizou a metáfora como procedimento constitutivo. O emprego da metáfora, segundo Joly (1996), expressa uma determinada linguagem de forma rica, criativa, inesperada e cognitiva. Neste último caso, a comparação de dois termos, o implícito e o explícito, reivindica a imaginação e a exploração de pontos em comum entre o que está implícito e o que está explícito na mensagem.

A imagem simbólica demonstra uma fogueira acesa e sustentada com três patas com cabeças de camelos, totalmente difusas, em direções distintas, que queimava uma espécie de bandeira triangular moldada com expressões que se reportam aos nomes dos responsáveis pela elaboração do Regulamento de Instrução Pública, a saber, Álvaro Jorge, Affonso Teixeira de Freitas e João Lagos. Da fumaça formada emanam os termos "asnice", "tolice", "burrice" e "camelice", para se remeterem aos reformistas e às suas concepções desvencilhadas de uma proposta convincente aos olhos da revista.

A charge apresenta uma espécie de legenda que enaltece a sua construção imagética: "O fogo da intellingencia da spientissima commissão que organisou o 
monummental regulamento de instrucção pública do Paraná e que é a oitava maravilha mundial pelas burrices que encerra" (O OLHO DA RUA, n. 19, 18 de janeiro de 1908, s.p.).

Tanto a charge quanto os vocábulos utilizados constituíram-se de maneira pejorativa. Por intermédio de uma linguagem metafórica, a imagem de camelo expressa a visão de muito trabalho realizado sem maestria e, portanto, mera perda de tempo. O termo "burrice" se soma aos demais para conotar a ausência de pensamento coerente para o tratamento devido da temática.

As críticas de $O$ Olho da Rua não se limitaram simplesmente aos responsáveis pela elaboração do regulamento de Instrução Pública de 1907. São críticas ao próprio momento histórico vivido pelo Brasil em decorrência da dificuldade de efetivar uma instrução capaz de alfabetizar uma nação analfabeta, promover escolarização primária e, em concomitância, desenvolver um país republicano moderno e civilizado.

Um aspecto que mais chama a atenção na charge remete para a semelhança entre a imagem triangular que evocava os reformistas e a bandeira da Inconfidência Mineira (1789) sendo queimada. A relação entre a bandeira da Inconfidência Mineira, que trazia originalmente a expressão latina "Libertas quae sera tamen" (Liberdade ainda que tardia), com os nomes dos elaboradores do Regulamento de Instrução Pública, acena para o retrocesso da própria República.

Há de se considerar que a imagem da própria República foi estruturada pela mediação entre o imaginário da população relacionado à ideia de modernidade e de progresso decorrentes da Proclamação da República. Na construção desse imaginário, heróis foram construídos. O nome de Tiradentes foi recuperado, pelos idealizadores da República, como o grande herói brasileiro; esse herói ligava a República e a Inconfidência Mineira, auxiliando o descarte da figura de Dom Pedro I, simbolicamente associado à Monarquia, ou seja, era a imagem de Tiradentes que se vinculava aos ideais republicanos (CARVALHO, 2017).

Possivelmente, na vertente do periódico, os elaboradores do Regulamento de Instrução Pública de 1907 estavam queimando os ideais de progresso e de modernidade republicanos e, em consequência, limitaram o desenvolvimento da própria instrução pública e a formação do cidadão republicano (que deveria ser civicamente orientado). Ou seja, queimar a "bandeira da Inconfidência Mineira" 
apregoou as dificuldades na proposição de uma instrução republicana que desse conta de unificar as bases de uma educação com potencial de romper com o imaginário monarquista.

Dessa forma, observamos a construção de sentidos e significados atrelados às formas de representação intentadas pelo periódico como formadoras de opiniões e de posicionamentos por parte dos leitores (CHARTIER, 1988, 1998). Essa representação "vendia" o ideal republicano e objetivava que os leitores o "comprassem".

É conveniente perceber o motivo pelo qual a revista declarou serem os elaboradores do regulamento incapazes para tal exercício. Na edição 19 (1908) observamos que uma das questões centrais se voltou ao distanciamento da proposta se comparada ao âmbito de aquisição e aderência a uma pedagogia moderna: "Sob o ponto de vista da pedagogia moderna o tal monstro nos apparece como coisa indefectível, defeituoso em suas múltiplas arestas, de ignorância incomensurável” (O OLHO DA RUA, n. 19, 18 de janeiro de 1908, s.p.).

Destaca-se que a noção de pedagogia moderna ganha seu tom para a educação dos paranaenses. Para se compreender a visão do periódico sobre o sentido atribuído à pedagogia moderna há de se perceber que, segundo Rossi (2017), os projetos educacionais na Primeira República (1889-1929) brasileira se relacionavam com o pensamento moderno. O pensamento moderno firma as suas raízes na mobilização intelectual do século XVIII, conhecido como o Século das Luzes. Desse modo, a nação brasileira é herdeira desse legado, sobretudo quando o aparato pedagógico se alicerçou nos princípios da escola pública, única para todos e universal. A educação assume, então, posição de destaque por ter potencial de retirar o sujeito da menoridade, segundo o pensamento de Immanuel Kant (1724-1804). Retirar o sujeito da menoridade era impeli-lo à liberdade pela via da autonomia completa da razão.

Essa educação, balizada pelo exercício pleno da razão, somava-se ao construto da democracia e produziria a liberdade, a igualdade e a justiça. Nesse viés, nos séculos XIX e XX vários projetos educacionais concatenados com os princípios de escola pública, laica, gratuita, universalizada para ambos os sexos, foram linha de referência para a nação. Rossi (2017) esclarece, contudo, que todos esses princípios não se efetivaram da mesma forma no Brasil, cujos contornos foram singulares e distintos 
dos delineados no século XVIII. No Brasil, o intento era unificar e desenvolver a democracia e alavancar e conclamar a participação da população na construção da sociedade, fator preponderante para as defesas feitas em relação à escola pública para todos por parte dos governos e dos intelectuais.

Como em cada estado brasileiro, as reformas deflagradas tiveram especificidades, Dario Vellozo (1920), na obra “Compêndio de Pedagogia”, divulgada pela primeira vez em 1907, representa o ideário de pedagogia moderna no estado do Paraná, assim como representa este ideário na lógica do periódico, devido à proximidade apresentada com esse intelectual, pois, Dario Vellozo (1886-1937) foi uma espécie de "herói anticlerical" apresentado pelo periódico (O OLHO DA RUA, n. 49, 20 de março de 1909, sp.).

Schaffrath (2014) esclarece que o "Compêndio de Pedagogia" marcou a história do ensino paranaense e a produção local vinculada ao preparo dos profissionais para o magistério primário no Paraná; circulou em um momento cujas contradições inerentes às proposições pedagógicas para a escola brasileira estavam acaloradas e expressou as singularidades de uma proposta de pedagogia moderna especificamente local, ou seja, o "Compêndio de Pedagogia" relacionou-se diretamente com a sociedade paranaense, sobretudo na figura de seu autor como escritor, intelectual, cidadão e como docente da mesma instituição onde o compêndio foi posto em circulação.

Vellozo (1920) orientou que a pedagogia era a ciência e a arte da educação; ensinaria o professor a ensinar os alunos por meio da indicação dos meios, dos preceitos e das regras pertinentes ao ensino. A educação escolar assumiu o direcionamento de reunir todos os esforços cabíveis para o desenvolvimento das faculdades físicas, intelectuais, morais, estéticas no indivíduo diante do desafio de formar cidadãos republicanos civicamente orientados.

A educação física seria a mola propulsora para a formação de indivíduos robustos e sadios, formação essa alicerçada na ginástica e na higiene. A educação intelectual se realizaria pelos sentidos (tato, visão, audição, paladar e olfato) imprescindíveis ao desenvolvimento da percepção, justamente por orientar a mente, proporcionar o saber, o conhecimento da verdade por intermédio da ciência. A educação moral voltava-se ao desenvolvimento e à formação da vontade, 
estabelecimento de normas balizadoras da conduta, ensinando deveres e virtudes afinadas com o bem. A vontade bem conduzida, disciplinada, era a mola propulsora da ação moral e da conduta, pois o objetivo maior da educação moral era desenvolver a prática da virtude por cultivar os sentimentos superiores, do bem com vistas a instrumentalizar o sujeito no estabelecimento de um determinado julgamento. Por sua vez, a educação estética permitiria o desenvolvimento das faculdades inerentes à criação, ao sentimento artístico e ao amor ao belo na medida em que a educação estética enaltecia e elevava o sentimento moral (VELOZZO, 1920).

No tocante à educação cívica, referência máxima da educação escolar, era visualizada como aquela cuja orientação iria convergir nos ensinamentos que orientariam o cidadão em relação aos seus direitos e deveres (com ênfase nos deveres) (VELOZZO, 1920). Depreende-se, dessas colocações, a seguinte assertiva: a formação de cidadãos, para bem servirem a família e a pátria, encontra na educação física, intelectual, moral e estética fundamentos a torná-los aptos ao exercício dos deveres cívicos direcionados à construção da nação. Ou seja, a pedagogia moderna pretendida pelo periódico atravessa a função da escola, a saber, investir na formação de cidadãos aptos e conscientes (civicamente) de suas ações diante da família e da nação brasileira.

No corpo do regulamento elaborado em 1907 encontram-se algumas passagens expressivas, possivelmente, da ausência dessas bases sólidas, aos olhos da revista, para instruir civicamente os paranaenses. $O$ artigo $1^{\circ}$ expôs: "O ensino popular tem por fim promover a educação intellectual, moral e physica, e é dividido em ensino público e ensino particular” (PARANÁ, 1907, p. 128). Na sequência, o artigo 34 prescreve: “A educação moral e civica não terá, em caso algum, o caráter de curso theorico ou philosophico, mas será comunicada em forma experimental simples" (PARANÁ, 1907, p. 132).

Então, como se lê no artigo $1^{\circ}$ do Regulamento, a educação cívica não é mencionada. Apenas no artigo 34 o documento esclarece que a educação cívica se desdobrava/fazia parte da educação moral. A educação moral e cívica deveria ser comunicada de modo experimental simples, sem deter-se em temáticas de caráter teórico e filosófico. A simplicidade com que a educação moral e cívica foi tratada converge para as críticas do periódico. Se se queria uma nação com cidadãos 
civicamente orientados, o assunto não poderia ter sido tratado de maneira secundária e simplista.

Observa-se, no discurso divulgado por $O$ Olho da Rua, que as críticas endereçadas aos três responsáveis em reformular a instrução pública, além de direcionadas a um ataque pessoal a esses personagens, tocam na questão da ineficiência do Estado em subsidiar financeiramente a instrução pública, sobretudo a primária, e ineficiente para fornecer bases consistentes para o seu desenvolvimento e para o desenvolvimento do próprio estado do Paraná.

Atrelando-se ao exposto, a terceira edição do periódico em 1907, em sua segunda capa, trouxe uma charge intitulada "Instrucção" (Figura 2), produzida por Herônio, pseudônimo de Mário de Barros (1879-1931), demonstrativa de um diálogo entre a instrução pública, ilustrada por uma mulher com uma pena atravessada no cabelo e um livro na mão esquerda e os três responsáveis pela elaboração da reforma da instrução pública em 1907, Álvaro Jorge, Affonso Teixeira de Freitas e João Lagos, virados de frente para a mulher, respectivamente:

Figura 2 - Charge "Instrucção" de Herônio

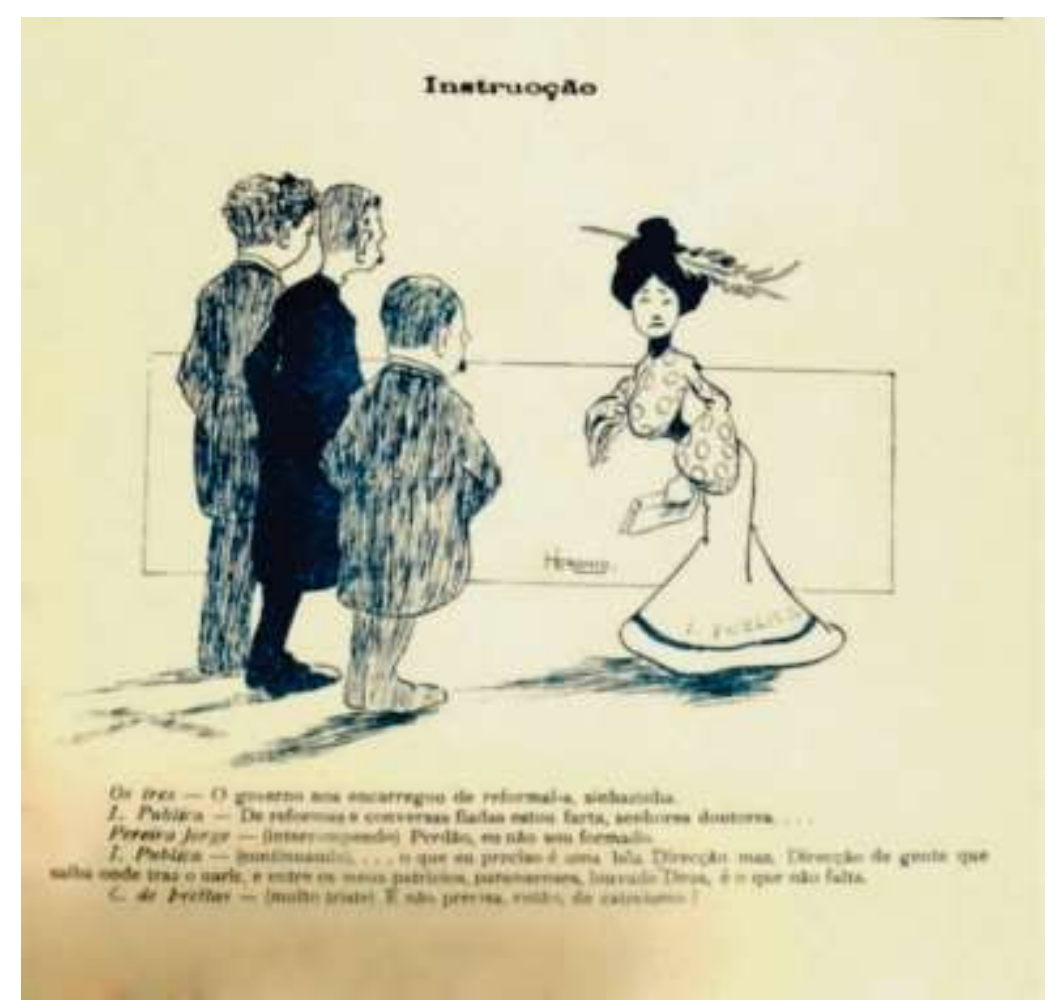

Fonte: O Olho da Rua, n. 3, 11 de maio de 1907, s.p. 
Vê-se, na imagem, tomada como ícone, a comissão responsável pela elaboração do Regulamento de Instrução Pública direcionados para um a mulher figurativamente posicionada para representar a Instrução Pública. A instrução pública manifestou seu descontentamento ao esclarecer que estava farta de reformas e de conversas fiadas. Vemos a mulher, a instrução pública, retratada com uma expressão facial cansada e de angústia, vestida com um vestido que lhe apertava demasiadamente a cintura, cabelos presos em forma de coque, uma pena, possivelmente utilizada para escrever, atravessada no coque e um livro em uma das mãos. A mulher, ao manifestar o descontentamento com as reformas e conversas fiadas, denota que estava cansada de se "vestir", de ser "reformada" de distintas formas, por pessoas que não sabiam dirigi-la adequadamente e cobra dos homens uma solução.

Há de se perceber que a instrução é uma categoria ideológica da pedagogia moderna e importante no início da República por ter a atribuição de difundir os conteúdos e os valores cívicos compatíveis com a constituição de uma identidade republicana. A constituição de uma identidade republicana parte do pressuposto de que os membros de uma mesma cultura são capazes de compartilhar um conjunto de conceitos, de imagens e de ideias que possibilitam sentir, refletir e interpretar o mundo de modo semelhante, justamente porque compartilham os mesmos códigos culturais (HALL, 2016). Por isso, a instrução, se unificada à educação, juntas eram capazes de impulsionar o compartilhamento dos mesmos códigos culturais entre os membros de uma mesma cultura.

Para Vellozo (1920), a verdadeira finalidade do ensino não é meramente instruir, é educar. Instruir é o ato de ministrar o saber aos outros e educar é o ato de persuadir de modo consciente. Nessa lógica, instrução e educação deveriam caminhar lado a lado. Caso contrário, a escola seria capaz, apenas, de cumprir a função de ensinar o ler, escrever, contar, porém não ensinaria a importância do ler, escrever e contar para a vida em sociedade, para ações civicamente orientadas.

Retornando a análise da charge (Figura 2), tem-se retratada uma mulher/instrução pública inviável e à mercê dos desencontros inerentes à instrução pública. A representação da mulher relativa à instrução pública é intencional. Veríssimo (1906) inseriu a instrução da mulher, primeira educadora do homem, como 
um dos temas centrais de suas discussões sobre educação nacional. Para que as mulheres fossem participantes da educação da nação era indispensável instruí-las, ultrapassando a sua tendência a ser carinhosa, por exemplo, e oferecer-lhes uma educação mais inteligente, ampliada e atrelada aos seus deveres, às suas responsabilidades diante do mundo e da humanidade; uma educação mais completa se comparada à educação das gerações anteriores, uma educação integral e enciclopédica, não no sentido de torná-la conhecedora profunda de uma determinada área, mas para que tivesse condições de participar do projeto de constituição da nação brasileira. Se, portanto, a pretensão era mudar e construir o sentimento de nação brasileira, favorecer de modo intencional sua evolução com o intuito de posicioná-la em um lugar de destaque no mundo, haveria de se começar, indiscutivelmente, pela educação da mulher.

A mulher é uma representação tanto para a instrução pública quanto daquela que deveria passar por um processo formativo com vistas a somar forças na empreitada da educação brasileira. Para reconfigurar a sociedade que se objetivava progressista e bem esclarecida para regenerar a nação, a escola passou a ser interpretada como instituição que ama, educa, ampara e domestica. Essa visão de escola alavancou a feminização do magistério no início do século XX, pois delegou à mulher a responsabilidade em moralizar os costumes e de guiar a infância. Nesse viés, constrói-se, por meio da tríade mulher-mãe-professora, a ideia de que a mulher possuía a capacidade natural de instruir e de educar com o intento de formar consciências (ALMEIDA, 2006).

A respeito do caráter emergencial de reformar a Instrução Pública nacional e, em específico, a instrução pública do estado do Paraná, situamos o ato de reformar a instrução como insuficiente. Quando a instrução pública diz: “[...] o que eu preciso é uma bôa Direcção mas, Direcção de gente que saiba onde traz o nariz e entre os meus patrícios, paranaenses, louvado Deus, é o que não falta" (O OLHO DA RUA, n. 3, 11 de maio de 1907, s.p.), além de demonstrar o descontentamento com a direção da instrução pública e, respectivamente, com os membros da comissão destinada a elaborar o Regulamento de Instrução Pública de 1907, o cerne da questão é que no Paraná havia outros sujeitos aptos para essa função e, acima de tudo, com conhecimentos para tal empreitada. 
Essa empreitada expressava um anseio específico do periódico, mas, de certa forma, se entrecruzava com os anseios republicanos, isso porque a transição da República caracterizou-se por um volume expressivo de reformas para a área educacional. Atrelando-se ao que a charge demonstrou, o periódico captou esse volume e expressou-se de modo a denotar que, se as reformas fossem suficientes para solucionar os problemas da Instrução, já teriam encontrado rotas para solucioná-los.

As preocupações prioritárias das reformas empreendidas tinham como ponto focal a construção de uma unidade na nação com ênfase no ensino popular e que carecia, antes de mais nada, de alfabetização. Esse ponto focal impulsionou a criação de novas instituições, a formulação de aparatos legais com vistas a profissionalizar, normatizar e sistematizar a escolarização dos sujeitos integrantes das camadas populares e a homogeneização dos costumes, do ordenamento e dos hábitos da população (ROSSI, 2017). Por isso, a escolarização primária era de suma importância para consolidar uma nação moderna e civilizada.

Nos liames da construção desse modelo, a separação do poder clerical do poder estatal preponderou. Isso se manifestou na charge "Instrucção" (Figura 2) ao demonstrar C. de Freitas triste ao levantar um questionamento aludindo se a instrução pública não precisava de catecismo - detalhe intencional retratado pelo chargista Heronio (Mario de Barros) e conotativo da perspectiva anticlerical da revista.

A insatisfação da revista $O$ Olho da Rua, no que perpassa as divergências de posicionamentos entre os clericais e os anticlericais, materializou-se na edição 4 de 1907 via uma charge intitulada "Nhê resuma" (Figura 3), cujo significado era "não compreendo", assinada por Sylvio, pseudônimo de Aureliano Silveira (1879-1928), capaz de esboçar a cena de uma escola dirigida por freiras polacas, polonesas e ilustra a ação das freiras em um escola primária de imigrantes — essa cena refere-se ao fazer prático da escola primária. 
Figura 3 - Charge "Nhê resuma", de Sylvio, sobre uma escola de freiras polonesas em Curitiba

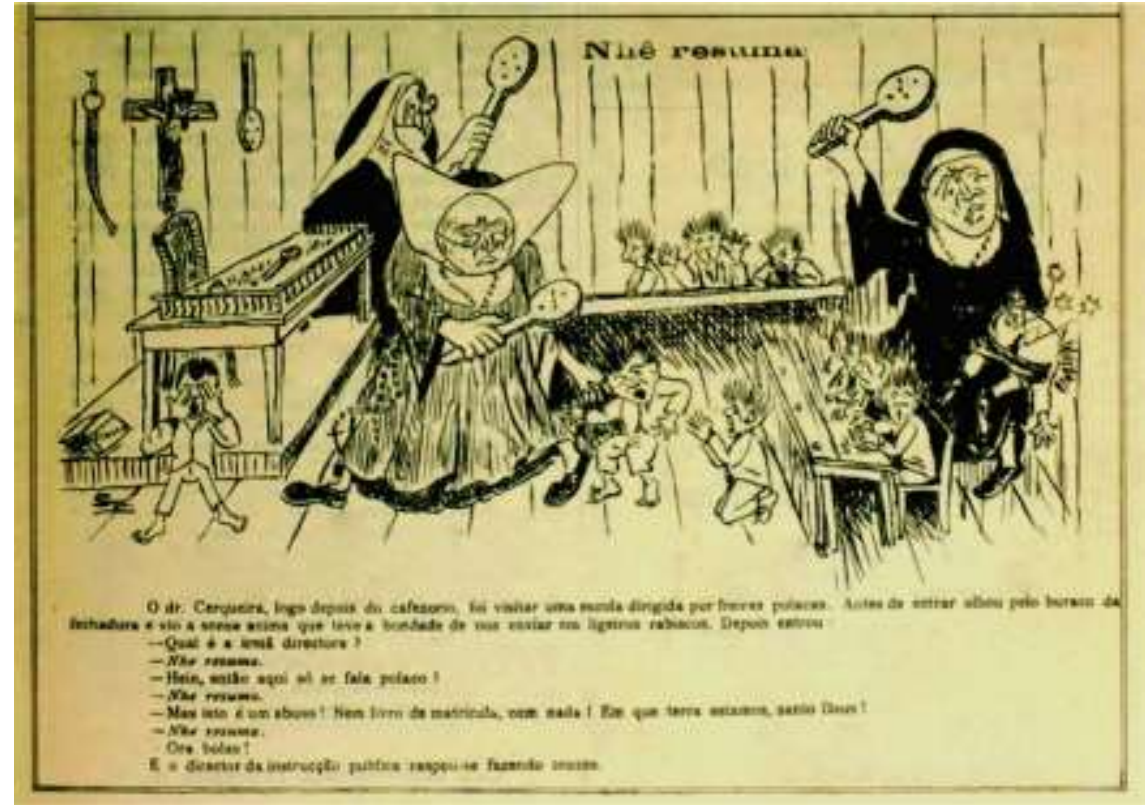

Fonte: O Olho da Rua, n. 4, 25 de maio de 1907, s.p.

A charge icônica mostra uma sala de aula organizada por freiras polonesas. $\mathrm{Na}$ parede identifica-se uma imagem de Jesus Cristo crucificado e instrumentos utilizados para a punição física dos alunos. A estrutura organizacional da sala era composta por uma mesa e uma cadeira em cima de um tablado e duas mesas compridas e cadeiras para acomodar os alunos, semelhante aos bancos de uma igreja.

A semelhança dos bancos para acomodar os alunos com os bancos das igrejas reporta-se a uma das discussões propostas por Hobsbawm (1997), para quem, uma das principais tradições inventadas no século XIX, na Europa, foi a educação primária. A educação primária era equivalente à tradição da própria igreja, por isso os bancos da igreja e os bancos da escola das freiras polonesas, retratados na charge, se assemelharam e apresentaram equivalência.

Na charge há uma freira, vestida com hábito diferente, no centro da sala dando palmatórias em um aluno, seguido de duas freiras exercendo a mesma ação. O "terror" dos alunos se sobressaiu e sugeriu que não entendiam o porquê dos castigos físicos. Vê-se certo apelo sinestésico na charge, quer dizer, a charge visa produzir sensações não apenas visuais, mas também sensações táteis, faciais, corpóreas remetidas ao resultado do disciplinamento desdobrados da punição física, dos castigos (SANTAELLA, 2005). 
A palmatória como meio de disciplinar as crianças é uma forma de crítica à pedagogia tradicional. A charge, ao expor a imagem de Jesus ao lado da palmatória, o fez de modo a ironizar o clericalismo, pois sugeriu a contradição entre Jesus, símbolo do amor, e a palmatória, símbolo do castigo e da dor.

Se a punição servia como aparato pedagógico de ensino e aprendizagem na pedagogia tradicional, a crítica da revista $O$ Olho da Rua ocorreu porque os anticlericais eram contrários à punição. Na visão de Velozzo (1920), a criança se educava pelo exemplo e, quando inserida na instituição escolar, ela deve complementar e corrigir a educação oferecida pela família. Por isso, Velozzo (1920) alertava o professor a ter paciência e piedade no trato com as crianças para não as maltratar. A disciplina, o respeito e a força moral do professor não o eximiam do trato delicado, ameno e amoroso com as crianças.

O diálogo contido na charge situa, como forma de ataque, o Cerqueira, Diretor de Instrução Pública à época, como o responsável por enviar os rabiscos de uma cena vista por ele pelo buraco de uma fechadura, sendo que, logo após, adentrou-se na sala e questionou a respeito de quem era a irmã diretora. A resposta veio por meio da expressão polonesa "nhê resuma", que significava "não entendo". Logo em seguida, questionou se naquele espaço só se falava a língua polaca, sendo que a resposta foi "nhê resuma" novamente. Cerqueira acenou para o absurdo da ocorrência e destaca que, na referida escola, não havia nem livro de matrículas, nem nada, denotando o distanciamento entre a realidade ilustrada e o mínimo necessário para o funcionamento de uma escola primária. Ao encerrar o diálogo, o diretor geral faz o sinal da cruz, expressão vinculada à contradição de o diretor geral questionar a estrutura organizacional da escola e, ao mesmo tempo, defender, nas entrelinhas, o viés clerical (BALHANA, 1980).

Outro detalhe que chamou a atenção na charge é o de um livro cívico jogado no chão do tablado da mesa das professoras freiras, denotativo da não observância da formação cívica dos republicanos. Os conteúdos embutidos no programa da educação cívica, além de incluírem a valorização do que era produzido pela própria nação, incluíam a instauração de datas comemorativas como alavancas criadoras de emblemas condizentes com a valorização "dos grandes feitos nacionais". No estado do Paraná, esse programa incluía a instrução por meio do estudo da organização 
constitucional do país, do direito público, dos direitos e das garantias institucionais, das qualidades do cidadão apto e consciente de seus deveres, da soberania nacional, do Estado, dos poderes - executivo, legislativo e judiciário —, da organização dos estados e dos municípios. Todos esses pontos habilitariam o cidadão a bem servir a humanidade, a pátria e a família (VERÍSSIMO, 1906; VELOZZO, 1920).

A charge ainda toca na questão dos imigrantes no Paraná. Renk (2013) aponta, dentro do cenário do estado do Paraná que, se levarmos em consideração o período que vai do final do século XIX até 1938, havia uma quantidade superior a 220 escolas étnicas polonesas e ucranianas que se achavam totalmente à margem do sistema público de educação. As instituições escolares formavam uma espécie de rede de ensino com o apoio da Igreja Católica e associações culturais comunitárias, sendo que pouco ou nada ensinavam da língua materna. Essas escolas eram caracterizadas como religiosas e leigas.

Para Wachowicz (1984), no estado do Paraná, os imigrantes instalavam escolas em suas localidades com uma organização distinta daquela das escolas públicas, pois as organizavam de acordo com as suas tradições europeias e os interesses do grupo. Essas escolas foram progressivamente desativadas em decorrência das campanhas de nacionalização.

Em correspondência com a charge, todas as vezes que a resposta do diálogo se consubstanciava seguida da resposta "Nhê resuma", expressou parte do movimento histórico desses tipos de escola centradas em suas línguas de origem. Se se quiser comparar, ainda que só por hipótese, a escola da charge, então fica unificada a crítica tanto à sua estrutura pedagógica e didática, clerical e pautada nas punições físicas, quanto à expansão dessas escolas no estado do Paraná.

Outro dado relevante reporta-se à forma de organização do espaço escolar disputado pela Igreja Católica e por lideranças consideradas laicas (RENK, 2013). Esse elemento ancora a lógica da charge, por ser capaz de demonstrar a visão do periódico baseada, por um lado, ao repúdio à escola dirigida por padres e freiras e, por outro, à falta de competência do estado, representado por Cerqueira, em organizar uma proposta de instrução pública para além dos liames clericais. Não foi de forma aleatória que o livro que continha conhecimentos sobre o civismo estava jogado e, sem utilidade, dentro da escola polaca. 
As divergências relativas às escolas primárias religiosas não se encerraram com a charge supramencionada. A próxima charge (Figura 4), intitulada "Collegio religioso em Palmas" (O OLHO DA RUA, n. 11, 7 de setembro de 1907, s.p.), elaborada por H, pseudônimo de Mário de Barros (1879-1931), sugere aspectos relevantes a esse respeito e remete-se, assim como a charge anterior, ao fazer prático da escola primária:

Figura 4 - Charge "Collegio religioso em Palmas" elaborada por H

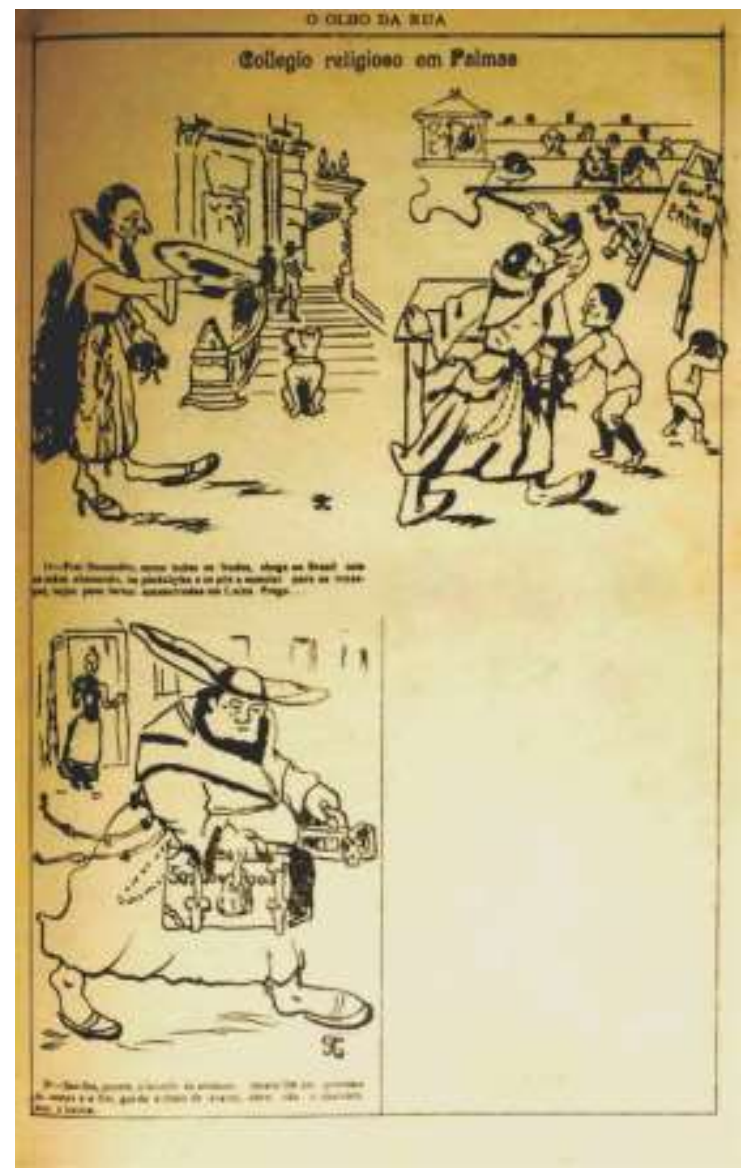

Fonte: O Olho da Rua, n. 11, 7 de setembro de 1907.

Essa charge icônica, diferente das demais, apresenta uma narrativa imagética para demonstrar uma sucessão de fatos. É composta por três cenas, envolve uma crítica aos padres e às escolas clericais. Na primeira cena, o frei Menandro é uma amostra da condição como os padres chegavam ao Brasil, sem recursos financeiros. Para tanto, se colocou a esmolar para as crianças cujos pais haviam falecido, possivelmente residentes em um orfanato, com a finalidade de arrecadar dinheiro. 
A segunda cena explicita a abertura de uma escola de padres, fundamentada em um regulamento forte. Nota-se que a expressão "regulamento forte" está grifada em itálico na charge. Pelos indicativos levantados, a expressão tece uma relação com as limitações em materializar uma escola desvinculada das ideologias e das doutrinas da Igreja Católica e sem punições físicas. A estrutura da sala de aula expressou isso. Ao fundo da sala, notamos a presença de um confessionário. A organização dos alunos em bancos, semelhantes à organização de uma Igreja Católica, emoldura os semblantes assustados devido à punição severa empregada pelo frei chicoteando um dos alunos. $\mathrm{Na}$ frente da sala, uma mesa e o frei em posição de autoridade e fúria, punindo fisicamente alguns alunos. Inclusive um deles estava amarrado junto à mesa.

Segundo se levantou na análise da charge sobre a escola das freiras polacas (Figura no 3), nota-se, novamente, a escola primária como uma tradição inventada no século XIX e como desdobramento da tradição da própria igreja. Além disso, temos na charge a figura de um frei, dado a sua pobreza, tornando-se professor. Isso se aproxima com o apresentado por Hobsbawm (1997), que comparou os professores aos frades pobres (instituteurs — em francês) e não ao clero mais alto.

$\mathrm{Na}$ sequência, não se retira da segunda cena da charge nenhum dispositivo especificamente pedagógico como meio de ensino, pois o que predomina é a punição. Trata-se de características semelhantes e identificadas na charge anterior ilustrativa de uma escola dirigida por freiras polacas.

$\mathrm{Na}$ terceira cena vê-se o frei fugindo devido a um processo, em decorrência do meio punitivo empregado e, hipoteticamente, pela falta de adequação da escola aos ditames oficiais. Havia uma única observadora da fuga do frei, nessa cena, gordo e cheio de dinheiro por baixo do chambre, roupão caseiro masculino, ou seja, o frei havia colocado o dinheiro arrecadado na escola por baixo da batina e colocou o chambre e um chapéu para se disfarçar e fugir das consequências do processo. Assim, o interesse dessa escola de padres não apresentou nenhum elemento voltado ao processo de ensino-aprendizagem dos alunos, pois era totalmente voltada a um modo de obter dinheiro e apregoar a punição, principalmente a punição física. Foi justamente isso que a revista $O$ Olho da Rua criticou.

Rossi (2017) afirma que, na Primeira República (1889-1929), os trâmites pertinentes à escolarização primária se distanciavam dos mecanismos punitivos 
disciplinadores, tais como os castigos corporais dos tempos anteriores. O que os republicanos propunham eram diversas outras estratégias, essas atuantes no campo do disciplinamento intelectual das crianças e dos jovens. Ocorreu, então, que essa nova perspectiva esbarrou na má qualidade das escolas particulares dirigidas por padres, por desconhecerem direcionamentos didáticos e pedagógicos que superassem os atos punitivos e se vinculassem a uma instrução (e educação) compatível com o intentado pela recém-criada República.

\section{Considerações finais}

As críticas prioritárias da revista $O$ Olho da Rua, por meio das charges, apontaram para as limitações do poder estatal na materialização, uma instrução que afeta o novo regime político e uma escolarização primária fundamentada nos preceitos republicanos de modernização e de civilização. A presença do clericalismo nas escolas era predominante no início da República no Paraná, porém elemento retrógrado e obstáculo à nova organização político-social do país, na perspectiva da revista.

No caso específico da escola primária, foi alvo de críticas justamente por não cumprir com a sua função primordial, pois, enquanto elencasse como primordial a presença do clericalismo na escola, negaria a formação cívica dos cidadãos republicanos, analfabetos e que careciam de uma escola primária com bases firmadas na educação física, moral, intelectual e estética, conforme indicação de Vellozo (1920).

As narrativas das charges demonstraram uma representação específica do periódico, articulada aos preceitos de uma instrução pública, que afeta a proposta de pedagogia moderna advogada por Dario Vellozo (1920), para quem os princípios centrais dessa instrução, articulada à educação, deveriam convergir para o anticlericalismo na escola e ser capaz de educar civicamente os cidadãos, desde a tenra idade, ou seja, as charges demonstraram que a instrução pública e a escola primária necessitavam de um redirecionamento para que promovessem uma instrução articulada com a educação cívica e comprometida com o anticlericalismo. 


\section{Referências}

ALMEIDA, J. S. Mulheres na educação: missão, vocação e destino? A feminização do magistério ao longo do século XX. In: SAVIANI, D. et al. O legado educacional no século XX no Brasil. Campinas: Autores associados, 2006. p. 59-108.

BALHANA, C. A. F. Idéias em confronto. 177f. Dissertação (Mestrado em História) Universidade Federal do Paraná, 1980.

BLOCH, M. Apologia da história on o ofício do historiador. Trad. André Telles. Rio de Janeiro: Jorge Zahar, 2001.

BRASIL. Constituição da República dos Estados Unidos do Brasil. Constituição: República Federativa do Brasil. Brasília, DF: Senado Federal, 24 fev. 1891. Disponível em: < http://www.planalto.gov.br/ccivil_03/constituicao/Constituicao91.htm>. Acesso em: 17 dez. 2018.

CAPELATO, M. H. R. A imprensa na história do Brasil. São Paulo: Contexto; Editora da USP, 1998.

CARVALHO, J. M. A formação das almas: o imaginário da República no Brasil. 2. ed. São Paulo: Companhia das Letras, 2017.

CERTEAU, M. A escrita da história. Trad. Maria de Lourdes Menezes. Rio de Janeiro: Forense Universitária, 1982.

CHARTIER, R. A bistória cultural: entre práticas e representações. 2. ed. Trad. Maria Manuela Galhardo. Portugal: Difel, 1988.

CHARTIER, R. A aventura do livro: do leitor ao navegador. Trad. Reginaldo Carmello Corrêa de Moraes. São Paulo: Impressora Oficial do Estado de São Paulo: UNESP, 1998.

CHARTIER, R. Os desafios da escrita. Trad. Fúlvia M. L. Moretto. São Paulo: UNESP, 2002a.

CHARTIER, R. À beira da falésia: a história entre certezas e inquietude. Trad. Patrícia Chittoni Ramos. Porto Alegre: Editora Universidade, 2002b.

CURY, C. R. J. Educação nas constituições brasileiras. In: STEPHANOU, M.; BASTOS, M. H. C. (Orgs.). Histórias e memórias da educação no Brasil, vol. III: século XX. Petrópolis: Vozes, 2005. p. 19-51.

HALL, S. Cultura e representação. Trad. Daniel Mitanda e William Oliveira. Rio de Janeiro: PUC-Rio: Apicuri, 2016.

JOLY, M. Introdução à análise da imagem. Trad. Marina Appenzeller. Campinas: Papirus, 1996.

KAMINSKI, R. Gosto brejeiro: as revistas ilustradas e a formação de juízos estéticos em Curitiba (1900-1920). In: BREPOHL, M.; CAPRARO, A. M.; GARRAFONI, R. S. (Orgs.). Sentimentos na história: linguagens, práticas, emoções. Curitiba: Editora da UFPR, 2012.

LUCA, T. R. História dos, nos e por meio dos periódicos. In: PINSKY, C. B. (Org.). Fontes históricas. São Paulo: Contexto, 2005. p. 111-153. 
MACHADO, M. C. G. A política educacional paranaense nos anos iniciais da República 1889 a 1900. In: XXVI Simpósio Nacional de História - ANPUH. Anais... São Paulo, 2011.

MACHADO, M. C. G.; MELO, C. S. O ensino primário e a política educacional do Paraná. Diálogos, Maringá, v. 16, supl. espec., p. 207-227, dez. 2012.

OLIVEIRA, M. C. M. O ensino primário na Provincia do Paraná, 1853-1889. 1982. 375f. Dissertação (Mestrado em História) — Universidade Federal do Paraná, 1982.

OLIVEIRA, M. C. M. Políticas e investimentos do governo do Paraná na rede pública de ensino (1889-1930). EccoS, São Paulo, v. 8, n. 2, p. 385-405, jul./dez. 2006.

O OLHO DA RUA. Curytiba, ano I, n. 3, 11 maio 1907.

O OLHO DA RUA. Coritiba, ano I, n. 4, 25 maio 1907.

O OLHO DA RUA. Coritiba, ano I, n. 11, 7 set. 1907.

O OLHO DA RUA. Coritiba, ano II, n. 19, 18 jan. 1908.

O Caso da suspensão. O OLHO DA RUA. Coritiba, ano III, n. 49, 20 mar. 1909, sp.

PARANÁ. Regulamento da Instrução Pública do Estado do Paraná (Decreto no 31, de 29 de janeiro de 1890. Coleção Leis, Decretos e Regulamentos do Estado do Paraná. Curitiba: Arquivo Público do Paraná, 1890. p. 39-50.

PARANÁ. Constituição Política do Estado do Paraná (1892). Coleção Leis, Decretos e Regulamentos do Estado do Paraná. Curitiba: Arquivo Público do Paraná, 1892.

PARANÁ. Decreto no 93, de 11 de março de 1901. Regulamento da Instruçãa Publica do Estado do Paraná. Curitiba: Tipografia d’A República, 1901.

PARANÁ. Decreto n 479, de 10 de dezembro de 1907. Regulamento da Instrução Pública. Curitiba: Tipografia d’A República, 1907.

RENK, V. E. Escolas étnicas ucranianas e polonesas no Paraná: entre a legalidade e a manutenção da identidade étnica. In: VII Congresso Brasileiro de História da Educação, 2013.

ROSSI, E. R. A educação escolar primária na Primeira República (1889-1929). Série-Estudos, Campo Grande, v. 22, n. 45, p. 159-171, maio/ago. 2017.

SANTAELLA, L. O que é semiótica. São Paulo: Brasiliense, 1983.

SANTAELLA, L. Semiótica aplicada. São Paulo: Pioneira Thomson, 2005.

SCHAFFRATH, M. A. S. Os livros didáticos na escola normal de Curitiba (1876-1920): entre a universalidade e as singularidades da circulação da literatura pedagógica. 167f. Tese (Doutorado em Educação) — Pontifícia Universidade Católica do Paraná, Curitiba, 2014.

SCHELBAUER, A. R. Idéias que não se realizam: o debate sobre a educação do povo no Brasil de 1970 a 1914. Maringá: Editora da UEM, 1998. 
SEVCENKO, N. Introdução. O prelúdio republicano, astúcias da ordem e ilusões do progresso. In: SEVCENKO, N. (Org.). História da vida privada no Brasil - Volume III. São Paulo: Companhia das Letras, 1998. p. 7-48.

SOARES; L.; GALVÃO; A. M. O. Uma história da alfabetização de adultos no Brasil. In: STEPHANOU, M.; BASTOS, M. H. C. (Orgs.). Histórias e memórias da educação no Brasil, vol. III: século XX. Petrópolis: Vozes, 2005. p. 257-277.

VELOZZO, D. Compendio de pedagogia. Curitiba: Livraria Mundial França e Requião, 1920.

VERÍSSIMO, J. A educação nacional. 2. ed. Rio de Janeiro: Livraria Francisco Alves, 1906.

WACHOWICZ, L. A. A relação professor/Estado no Paraná tradicional. São Paulo: Cortez; Autores Associados, 1984. 